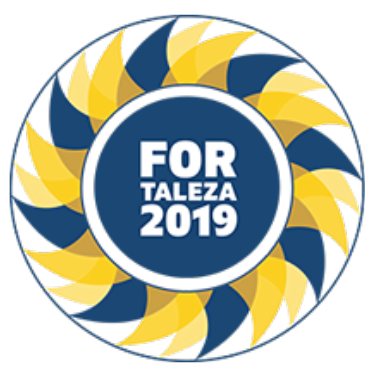

\title{
Cytomegalovirus Retinitis in a Patient with Systemic Lupus Erythematosus
}

ANA CAROLINA SCHONROCK ANA CAROLINA SCHONROCK (UNIPLAC, lages, SC, Brasil), João Pedro Villela Veiga Pereira da Cunha Pedro Villela Veiga Pereira da Cunha (UNIPLAC, Lages, SC, Brasil), Léo Müller Müller (UNIPLAC, Lages, SC, Brasil)

\section{BACKGROUND}

Cytomegalovirus (CMV) retinitis is a rare disease that occurs more frequently in patients with AIDS and CD4 lower than 50 cells / mm3. However, the number of reports is increasing from CMV retinitis in HIVnegative immunocompromised patients. SLE is one of the diseases reported that can lead to CMV retinitis due to its immunosuppressive therapy. However, this condition is not the most frequent cause of visual loss in the lupus, and the correct diagnosis is of great importance, since CMV retinitis, when left untreated, leads to rapid and irreversible visual loss. Its diagnosis is made by the evaluation of an experienced ophthalmologist through the evaluation of the fundus of the eye as well as retinography. We describe a case of a patient with SLE, HIV negative who evolved with unilateral partial visual loss due to CMV retinitis.

\section{CASE REPORT}

V.V., female, 54 years old, diagnosed with SLE for 8 years, on treatment with Hydroxychloroquine 200mg / day. There have been 2 months of use of Methotrexate $25 \mathrm{mg} /$ week and Prednisone $0.5 \mathrm{mg} / \mathrm{kg} / \mathrm{day}$ due to joint cutaneous activity with elevated ESR. The patient had a good clinical laboratory response, however, in the sixth week after follow-up, she complained of decreased visual acuity and light rays in the left eye. Ophthalmologic evaluation by retinography revealed retinal necrosis in the lower temporal artery, associated with retinal vasculitis and diffuse intraretinal hemorrhages (Fig 1). Due to suspected CMV retinitis, Ganciclovir EV 5mg / kg 2x day for 21 days followed by Valganciclovir 900mg / day for 6 months. The ophthalmologic evaluation, after Ganciclovir, revealed an improvement in vasculitis and stabilization of the necrosis area, with consequent formation of retinal fibrous scarring tissues (Fig 2).

\section{CONCLUSION}

The rapid evolution of CMV retinitis (weeks a few months), for complete visual loss, shows how important the correct diagnosis and immediate therapeutic institution is. To that end, the ophthalmologist should be aware of atypical pictures of visual loss in the lupus patient, since the most common causes of retinal lesion in SLE occur due to vasculitis with ischemia or retinal hemorrhage, which require treatment different from that caused by CMV. 